\title{
A survey on readiness of cloud based queuing management system implementation to mobile users
}

\author{
A. H. Mohd Saleh' ${ }^{1}$, N. A. Mohamed Radzi' ${ }^{2}$ W. S. H. M. Wan Ahmad ${ }^{3}$, C. B. M. Rashidi ${ }^{4}$ \\ ${ }_{1,2,3}$ Institute of Informatics and Computing in Energy (IICE), Department of Electrical and Electronic Engineering, \\ College of Engineering, Universiti Tenaga Nasional, Malaysia \\ ${ }^{4}$ Communication Engineering, Centre of Excellence School of Computer and Communication Eng., \\ Universiti Malaysia Perlis (UniMAP), Malaysia
}

\begin{tabular}{|c|c|}
\hline Article Info & ABSTRACT \\
\hline Article history: & \multirow{10}{*}{$\begin{array}{l}\text { Queuing Management System (QMS) has been used in medical facilities to } \\
\text { manage crowd systematically and reduce customer dissatisfaction. However, } \\
\text { customers that use conventional QMS needs to be within the facility to have } \\
\text { access to the QMS information. With the integration of mobile application } \\
\text { and cloud based QMS, customers are able to access QMS information } \\
\text { anywhere. However, migrating to a new technology requires a study on the } \\
\text { readiness of the system. Hence, the objective of this study is to understand } \\
\text { the effect of implementing QMS by investigating the effect of time } \\
\text { efficiency, cost efficiency, accessibility, reliability, variety, convenience } \\
\text { towards customer satisfaction. } 311 \text { respondents were given survey questions } \\
\text { with } 100 \% \text { response rate. The results were analysed using Statistical Package } \\
\text { for the Social Sciences. For reliability analysis, the survey questions were } \\
\text { proven to be valid, where factor analysis done supports the results to be } \\
\text { effective for further analysis. Correlation and regression analysis done also } \\
\text { show that there are influences between the independent variables and the } \\
\text { dependent variable. }\end{array}$} \\
\hline Received Jan 12, 2019 & \\
\hline Revised Apr 13, 2019 & \\
\hline Accepted May 4, 2019 & \\
\hline Keywords: & \\
\hline Cloud QMS & \\
\hline Mobile application & \\
\hline Queue management system & \\
\hline Statistical study & \\
\hline Survey & \\
\hline
\end{tabular}

Copyright $\odot 2019$ Institute of Advanced Engineering and Science. All rights reserved.

\footnotetext{
Corresponding Author:

Nurul Asyikin Mohamed Radzi,

Institute of Informatics and Computing in Energy,

Department of Electrical and Electronic Engineering,

College of Engineering,

Universiti Tenaga Nasional,

Jalan Ikram-UNITEN, 43000 Kajang, Malaysia.

Email: asyikin@uniten.edu.my
}

\section{INTRODUCTION}

Queue management system (QMS) is commonly found in facilities that has a needs to manage huge number of customers such as hospitals, governmental offices, financial institutions and educational institutions [1]. With QMS, customers will be able to estimate when they are going to be served fairly. However, customers that use QMS needs to be within the facility to have access to QMS information. In medical facilities, where time taken for a service can be long and the crowd can be high, waiting in queue physically leads to unnecessary cost and stress to the customers. In addition, there are medical facilities that have not yet implemented QMS due to the cost involved. With the development of cloud technologies, such concerns can be addressed. Integrating cloud technologies with QMS reduces the entry cost for an organization as the software and hardware are hosted remotely [2]. Organizations will be able to use resources as they want whenever they need, indicating lower exit cost, mitigating the risk of implementing new system [3]. Furthermore, with the gaining popularity of mobile application along with the integration of cloud technologies, customers will be able to access QMS information anywhere and anytime they want through the application. 
However, a thorough study on the impact of implementing cloud based QMS on mobile users in an urban area is yet to be studied. Hence, the objective of this paper is to understand the effects of implementing cloud based QMS towards customers by investigating the effect of the independent variables (IV), which are, time efficiency, cost efficiency, accessibility, reliability, variety and convenience towards the dependent variable (DV), which is customer satisfaction. The result of this research will help organizations to understand whether there is a needs of implementing a cloud based QMS in their premises. With the understanding, organization will be able to improve employee's productivity while increasing the customer satisfactions should they choose to opt for cloud based QMS. The layout of this paper is as follows: Section 2 will discuss on the literature review, Section 3 will be on the methodology, Section 4 on the results and discussions and the conclusion will be done in Section 5 .

\section{LITERATURE REVIEW}

\subsection{Waiting and Crowd}

Previous study in [4] shows that people in United States spend approximately 37 billion hours each year waiting in line, while in United Kingdom, another study shows that an average adult spends approximately one year of their lives in queue [5]. Queuing will cause psychological effects such as anxiety, waiting uncertainty, unexplained waiting time and unfair wait [6]. There are numerous evidence in the literature that illustrates the relationship between cost and waiting time. Farnworth [7] and Cullis et al. [8] agreed that there is an optimal waiting time from patient's perspective, proving that in health industry, the longer the wait, the higher is the treatment cost. From a medical perspective, there is a relationship between waiting time and health, as well as waiting time and cost. Cullis et al. [8] mentioned that waiting for treatment may affect health in multiple ways which may lead to cost-ineffectiveness. Simons et al. [9] stated that for patients seeking medical attention, monetary and time are equal factors when choosing services. People do not mind to pay more for faster services. Different study shows that long waiting time indicates poor organization process, which indirectly illustrates the lack of respect to their customers [10]. This proved that the longer the customers wait, the higher the organization will lose them. Visa Contactless study find that the people in the United Kingdom spend 18 hours per year in queuing, leading to retailer at the risk of losing loyalty customers [11]. The study also shows that $89 \%$ of the consumer decided to leave the business due to excessive queuing.

\subsection{The Importance of Queuing Management System}

Generally, QMS is used for congestion control to manage the flow of the organizations' customers, from the first contact with the organization to the time when the customers complete their transactions. Customer's flow can be categorized into seven processes based on Maitanmi et al. [12] which are prereception, reception, waiting, service, post-service, administration, and stochastic process. Waiting line systems models is used to illustrate different ways on how to use QMS [12]. In queuing theory, waiting line models is described as the calculation models from a management perspective that help organizations to make decisions on which waiting line models to be chosen. Important information from each waiting line models include waiting time, average customer's arrivals, service stations characteristics, and system disciplines. These models are derived from mathematical formulas and relations to obtain the productivity and operation effectiveness. The calculation includes but not limited to the probability that no customers in the line, average waiting customer in line, average customers in line and being served, the average time spends in line, the average time spends for the process excluding the service time, and the probability that customers need to wait for the service [12]. From the calculations, organizations can then design their waiting line models that best fit their needs, environment, and resources. When investigating the advantages of QMS, the benefits can be demonstrated from three perspectives: customers, employees, and managers. From the customers' perspective, QMS can reduce the waiting time at a location. In addition, QMS helps in speeding the service time since the queue is being managed by the system, instead of done manually [12]. From customers' perspective, QMS provides a sense of fairness, leading to an increase to customer's satisfaction including filling their time with other useful activities other than queuing. This may reduce their anxiety and increase satisfaction, and indirectly will improve the service quality [12]. From the organization's employees' perspective, their productivity and working efficiency can be improved with the help of QMS [12]. Organization's managers can also benefit from QMS, with reports generated allowing them to measure their subordinates' performance as well as to optimize resource allocation, manage subordinates' workloads, hence, providing a better service to customers [12].

There are studies involving different approaches to notify customers about the queue information. One study by Arun et al. [13] uses a Global System for Mobile (GSM) as well as the Short Message Service (SMS) technology to deliver messages to patients who has appointments with doctors. GSM modem can be used as an interfacing element between two mobile devices in a server-client architecture [14], hence, 
establishing a communication application. In addition, not only the queuing information can be notified to the customers through SMS, in an appointment based queuing, Global Positioning System (GPS) can also be used along with General Packet Radio Service (GPRS) to describe the location of customers and calculate the distance between customers and the organization's location making QMS more efficient and smart [15]. Here, the estimated waiting time and estimated time of arrival can be used by customers to decide when the optimum time to start heading to the location is. The integration of mobile communication together with cloud technology leads to a high potential in further improving QMS for a better customer satisfaction. However, a detailed study has to be done before implementing a new system in medical facilities. In this paper, the acceptance of implementing cloud based QMS towards mobile users will be investigated. Thus, the following section of this paper will focus on investigating the effect of time efficiency, cost efficiency, accessibility, reliability, variety and convenience towards customer satisfaction.

\section{METHODOLOGY}

This paper presents descriptive approach through surveys and meta-analysis approach through results obtained from the survey. This study can be considered as an exploratory research, and the correlation between the studied components and customer satisfaction will be further investigated, while considering the effect of integrating mobile application and cloud technologies with QMS. Based on Krejcie and Morgan [16], the appropriate sample size is 310 based on 1600 total population. The number of cases per medical facility per year is approximately 1600 or on average 31 cases per facility. Therefore, ten clinics are chosen for this study is to achieve 310 population taking into account that 31 patients per clinics will be used for samples. The research will be focused on small to medium clinics within Klang Valley, Malaysia. This area is chosen due to their high number of populations and residences' income range diversities. Other than demographics criterion, six IV will be considered in this study. All the IV will be studied against the DV, which is the customer satisfaction. The IV are time efficiency, cost efficiency, information accessibility, application reliability, functional varieties, and convenience or the ease of use of the mobile application. The reason why customer satisfaction is chosen as the DV aside from understanding the effect of IVs is due to the likelihood of customers' willingness to use such application given the sets of condition. The expected behaviour is the higher the customer satisfaction value, the higher the chances of users using the application to fit their purposes.

Studies about cloud technologies, the effects of waiting, QMS and mobile application developed are first done in order to establish survey questions used to obtain the results. Before the actual survey is done, a pilot study will be conducted to obtain the reliability, and the effectiveness of the survey on 100 respondents. After verifying that the result of the pilot study is acceptable, the survey questions will then be distributed around Klang Valley area, mainly Selayang, Damansara, Shah Alam and Bukit Jalil to 311 respondents. In addition to the survey result, interviews with the respondents as well as the employees of the facilities will also be conducted not only to support the result from the survey, but also to understand the nature of the results. The survey result from the pilot study as well as the actual survey will be analysed using Statistical Package for the Social Sciences (SPSS), which is a statistical tool to generate values that will be discussed in the next chapter. For the pilot study, only reliability analysis will be done in order to confirm the effectiveness of the survey. For the actual survey, two approaches are used to analyse the results: 1) descriptive analysis illustrated by charts and table for correlation between demographic attributes and customer satisfaction; 2) factor and correlation analysis between IVs and DVs. Correlation analysis will be able to conclude the relationship between the variables, on how the IV affects the DV, while factor analysis is to measure the gap for the components, if exist, for the DV. Factor analysis, will also be supported using the level of acceptance of Kaiser-Mayer-Olkin (KMO) index, as well as Bartlett's test [17].

In order to understand how reliable the proposed survey is, a pilot study is conducted. The pilot study must be performed before the actual data collection to prove that the survey results gathered will be able to support the results from the actual data collection. If the results from the pilot study is not reliable, then further correction must be made to the survey questions until an acceptable result is obtained. A different sample population is used for the pilot study, which can also be considered as the control group. Based on previous researchers, the sample size of a pilot study should be at least $10 \%$ of the size of the actual respondents [18, 19]. Using the rule mentioned by Roscoe, which states that the appropriate number of respondents should be between 30 and 500 [20], having 100 respondents is sufficient to determine the effectiveness of the survey questions. For the purpose of this study, the survey questions were distributed to 100 respondents who are using QMS in the Selayang area. From the result of pilot study, the reliability of the research instrument will be analysed using the same research tool, which is the SPSS. In order to measure the reliability of the study, Cronbach's alpha value, which is calculated using SPSS is used. From the value, the relationship of the survey questions within the same set of an IV can be determined. A good and reliable 
value for Cronbach's alpha must be at least 0.70, as stated by Anastasiadou [21]. In other words, for each of the IV, the correlation between each question can be considered to be acceptable, if and only if the Cronbach's alpha value is larger or equal than 0.70 [22]. Therefore, the results collected from the pilot study, based on 46 questions on 7 variables excluding the demographic questions, were good and reliable. Table 1 (column Pilot Study) shows the result of Cronbach's alpha for overall components for the pilot study. Based on the result it can be seen that the Cronbach's alpha value for all variables, even excluding the DV, show a result of higher that 0.70 . Hence, concluding the result from pilot study is good and reliable. A value of 0.964 for all variables show that the relationship between each question within the survey has a very good correlation. In addition, all IV also have a very reliable relationship, shown by the high value $(0.952)$.

\section{RESULTS AND DISCUSSION}

In this study, all respondents answered the survey through face-to-face interaction which were distributed to anyone waiting not only within the facilities but also around the vicinity of the clinics. There are a total of ten clinics involved directly and indirectly in this study. Two main analysis that will be conducted: descriptive and factor analysis. The first analysis will be on demographic background for all 311 respondents such as gender, residence, and nationality.

Figure 1 illustrates the results collected for the demographic background in this study. The second analysis will be focused on the relationship between the IVs such as time efficiency, cost efficiency and accessibility. The research tool used to analyse the data collected from the survey is the SPSS software where it will be used to aggregate and calculate the results for both analysis. The results will include reliability test of each IV and DV for the population within this study scope and discuss the results from the factor analysis as well as multiple regression tests. By conducting multiple regression tests, in addition to factor analysis, the level of relationship between IVs and DVs can be clearly illustrated.

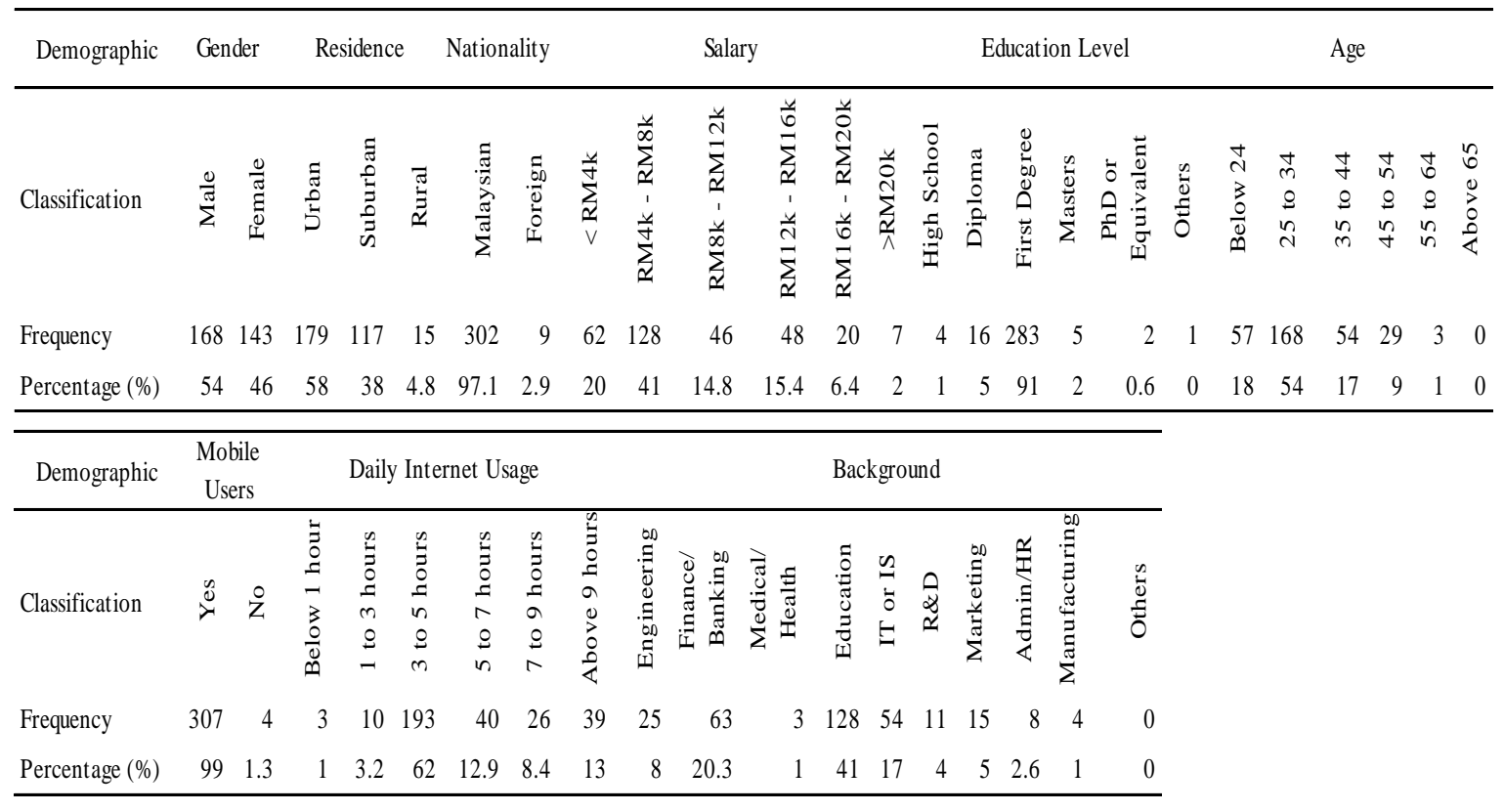

Figure 1. Demographic profile summary

\subsection{Reliability Analysis}

Reliability test was done for each of the variables on the results conducted for this study. The purpose of reliability test is to make sure that the variable is significant for data collected using the study of main population. Table 1 (column Actual Survey) illustrates the overall value of Cronbach's alpha for all variables as well as without including the DV. As can be seen from the results, both values show above 0.7, indicating that the correlations for all questions conducted for the survey is good and reliable [22].

Table 2 demonstrates the Cronbach's alpha value for each of the variables. In order to develop an effective survey, the results obtained from the survey must be verified to be valid and reliable. The validity of the results can be proven using the Cronbach's alpha values for each of the components from the reliability 
test where all values is recorded to be larger than the acceptable value of 0.7 . The values show positive results not only when the survey is done on clinics, but also during the pilot study as well. Therefore, it can be concluded that the first objective has been achieved which is developing an effective survey on the readiness of QMS implementation in clinics for highly populated area.

Table 1. Reliability Results on All Variables on Pilot and Survey Study

\begin{tabular}{ccccccc}
\hline \multirow{2}{*}{ Variable } & \multicolumn{2}{c}{ Cronbach's alpha $(>0.70)$} & \multicolumn{2}{c}{ Number of items } & \multicolumn{2}{c}{ Total Respondents } \\
& Pilot Study & Actual Survey & Pilot Study & Actual Survey & Pilot Study & Actual Survey \\
\hline All variables & 0.964 & 0.948 & 46 & 46 & 100 & 311 \\
All independent variables & 0.952 & 0.928 & 41 & 41 & 100 & 311 \\
\hline
\end{tabular}

Table 2. Reliability Analysis of each Variables

\begin{tabular}{cccc}
\hline \multirow{2}{*}{ Independent Variables } & Focus & \multicolumn{2}{c}{ Cronbach's alpha $(>0.70)$} \\
& & Pilot Study & Actual survey \\
\hline Time Efficiency & QMS and Mobile Application & 0.775 & 0.780 \\
Cost Efficiency & QMS and Mobile Application & 0.782 & 0.731 \\
Accessibility & QMS and Cloud Technologies & 0.732 & 0.719 \\
Reliability & QMS and Cloud Technologies & 0.778 & 0.744 \\
Variety & QMS and Customer Satisfaction & 0.916 & 0.907 \\
Convenience & QMS and Customer Satisfaction & 0.706 & 0.710 \\
\hline
\end{tabular}

\subsection{Factor Analysis}

Factor analysis is used to validate the data collected using the survey questions. The first key measurement used in this study is the KMO index. KMO value will be able to tell the differences between partial correlations and the original correlations, within the same set of variable. From [21], KMO value of above 0.90 shows a marvellous acceptance level, 0.80 to 0.89 is meritorious, 0.70 to 0.79 is middling, 0.60 to 0.69 is mediocre, 0.50 to 0.59 is miserable, and below 0.50 is unacceptable. In addition to KMO, Bartlett's test will also be used to investigate the relationship between correlation and identity matrix, hence, validating the redundancy between the variables. Using Bartlett's test, the null hypothesis can be rejected, if and only if the significance value is less than alpha value of 0.01 percent. Not only that the null hypothesis is rejected through Bartlett's test, the population matrix will also be considered as identity and the data collected are suited for the purpose of the study since there are correlations in the data. Another key measurement that will be investigated is the total variance of the factor analysis. Based on the standards in social science study, the total variance should be larger than $60 \%$, where components within one variable can explain $60 \%$ of the variance in one factor. Table 3 shows factor analysis results against an IV with KMO, Bartlett's Test and total variance.

Table 3. Factor Analysis Results

\begin{tabular}{cccc}
\hline Variables & KMO & Bartlett's Test & Total variance \\
\hline Time Efficiency & 0.620 & sig $=0.000$ & $87.772 \%$ \\
Cost Efficiency & 0.707 & sig $=0.000$ & $88.206 \%$ \\
Accessibility & 0.734 & sig $=0.000$ & $88.423 \%$ \\
Reliability & 0.528 & sig $=0.000$ & $93.193 \%$ \\
Varieties & 0.623 & sig $=0.000$ & $71.094 \%$ \\
Convenience & 0.560 & sig $=0.000$ & $88.473 \%$ \\
Satisfaction & 0.627 & sig $=0.000$ & $88.784 \%$ \\
\hline
\end{tabular}

The KMO generated from reliability and convenience show the values of 0.528 and 0.56 respectively. While the KMO values show a miserable acceptance value, the values are still acceptable since they are higher than the minimum KMO acceptance value of 0.50. On the other hand, the KMO values for time efficiency, varieties and satisfaction show the values of $0.62,0.623$ and 0.627 respectively, which are considered as mediocre. The KMO values for both cost efficiency and accessibility are recorded as middling. All variables indicate higher value than the minimum KMO requirement of 0.50 . The Bartlett's test for all variables show a value of 0.000 and lower than the significance level of $0.01 \%$, indicates that the null hypothesis is rejected and the correlation matrix is accepted as identity. In other words, the components or the questions used for each variables can be concluded to be valid and correlated to each other. The total variance for all variables are recorded well above the minimum standards of $60 \%$ according to the standards 
of social science. Therefore, based on the results provided in Table 3, all 55 questions used for all seven components can be concluded as valid and appropriate. Therefore, the second objective for this paper, where factor analysis method for validation of the survey questions has been achieved and completed.

\subsection{Correlation Analysis}

The next analysis conducted for this study is the correlation analysis between IVs and DVs. The purpose of such analysis is to determine the strength of relationships, if any, between the IVs and DVs. Based on the correlation coefficient categorization provided by Christine and John [23], coefficient value of 1 represents perfect correlation, 0.70 to 0.99 is strong, 0.30 to 0.69 is moderate, while 0.10 to 0.29 and 0 value are weak and zero correlation respectively. Table 4 shows the correlation analysis on time efficiency, cost efficiency, accessibility, reliability, varieties and convenience variables towards satisfaction. The $\rho$ value obtained for all variables is 0.000 which is less than $5 \%$ significant level (2-tailed), indicating that there is a relationship between all variables mentioned and satisfaction. Correlation coefficient values for time efficiency, cost efficiency, reliability and varieties are positive, indicating that customer satisfaction is higher when these variables are managed better. However, the relationship between accessibility and satisfaction is only moderate, since the value is 0.587 . Thus, accessibility variable has a moderate influence towards satisfaction. On the contrary, the strength of the relationship is moderate between convenience and satisfaction since the value of the correlation coefficient is 0.321 . In other words, while customer satisfaction can be increased through better convenience or more user-friendly the software can be, the effect is just as strong as compared to the other IVs.

Table 4. Correlation Analysis (CA)

\begin{tabular}{|c|c|c|c|c|c|c|c|c|c|c|c|c|c|c|c|c|c|c|c|c|}
\hline 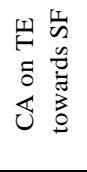 & $\mathrm{PC}$ & 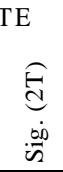 & $\mathrm{N}$ & $\mathrm{PC}$ & 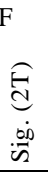 & $\mathrm{N}$ & 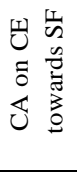 & $\mathrm{PC}$ & 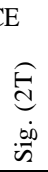 & $\mathrm{N}$ & $\mathrm{PC}$ & 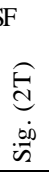 & $\mathrm{N}$ & 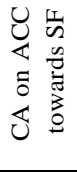 & $\mathrm{PC}$ & 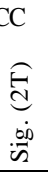 & $\mathrm{N}$ & $\mathrm{PC}$ & 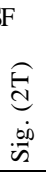 & $\mathrm{N}$ \\
\hline TE & 1 & & 311 & $0.914 * *$ & 0 & 311 & $\mathrm{CE}$ & 1 & & 311 & $0.917 * *$ & 0 & 311 & ACC & 1 & & 311 & $0.587 * *$ & 0 & 311 \\
\hline $\mathrm{SF}$ & $0.914 * *$ & 0 & 311 & 1 & & 311 & $\mathrm{SF}$ & $0.917 * *$ & 0 & 311 & 1 & & 311 & $\mathrm{SF}$ & $0.587 * *$ & 0 & 311 & 1 & & 311 \\
\hline 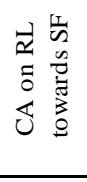 & $\mathrm{PC}$ & 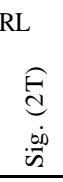 & $\mathrm{N}$ & $\mathrm{PC}$ & 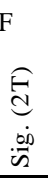 & $\mathrm{N}$ & 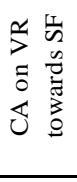 & $\mathrm{PC}$ & $\underset{\dot{0}}{\stackrel{\mathbb{N}}{\Delta}}$ & $\mathrm{N}$ & $\mathrm{PC}$ & 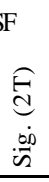 & $\mathrm{N}$ & 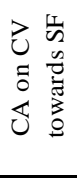 & $\mathrm{PC}$ & $\underset{\dot{0}}{\stackrel{\vec{N}}{\Delta}}$ & $\mathrm{N}$ & $\mathrm{PC}$ & $\underset{\dot{0}}{\stackrel{\vec{N}}{\Delta}}$ & $\mathrm{N}$ \\
\hline RL & 1 & & 311 & $0.829 * *$ & 0 & 311 & VR & 1 & & 311 & $0.761 * *$ & 0 & 311 & $\mathrm{CV}$ & 1 & & 311 & $0.321 * *$ & 0 & 311 \\
\hline SF & $0.829 * *$ & 0 & 311 & 1 & & 311 & $\mathrm{SF}$ & $0.761 * *$ & 0 & 311 & 1 & & 311 & $\mathrm{SF}$ & $0.321 * *$ & 0 & 311 & 1 & & 311 \\
\hline \multicolumn{21}{|c|}{$\begin{array}{l}\mathrm{PC}=\text { Pearson-Correlation; } 2 \mathrm{~T}=2 \text {-tailed; } \mathrm{SF}=\text { satisfaction; } \mathrm{TE}=\text { time efficiency; } \mathrm{CE}=\text { cost efficiency; } \mathrm{ACC}=\text { accessibility; } \mathrm{RL}=\mathrm{reliability} ; \\
\mathrm{VR}=\text { varieties; } \mathrm{CV}=\text { convenience }\end{array}$} \\
\hline
\end{tabular}

\subsection{Regression Analysis}

The regression analysis was also done for the purpose of this study to observe how the in IVs contributed to the DVs. According to Chang et al., the result of regression analysis will be able to determine the weight on how the IVs influence the DV [24]. For range of R-Squared value from $70 \%$ to $100 \%$, it is interpreted as strong correlation, while for $30 \%$ to $69.9 \%$ and $0 \%$ to $29.9 \%$ are moderate and weak correlation accordingly. Another approach to interpret the R-Squared value is using the Durbin-Watson test [25]. This test will further support the results obtained from the regression analysis. However, the purpose of the Durban-Watson test is to verify the autocorrelation between the IVs and the DVs. The values for DurbanWatson test falls between the ranges of 0 to 4 , where value close to 0 means positive autocorrelation, close to 2 is non-autocorrelation and close to 4 is negative autocorrelation.

Based on Table 5, the value for $\mathrm{R}$ for time and cost efficiency are 0.914 and 0.917 respectively, which indicate that the relationships between time and cost efficiency towards satisfaction have a strong correlation. R-Squares for both time and cost efficiency are $83.5 \%$ and $84 \%$, which also supports that the strength of correlation is strong. With Durbin-Watson test value closer to 2, with a value of 1.557 for time efficiency ad 1.454, the regression analysis results strongly suggest that the Satisfaction index is mainly influenced by both cost and time efficiency variable. $R$ square values for accessibility, reliability and variety 
are recorded at $34.4 \%, 68.7 \%$, and $58.0 \%$ respectively which all fall under "Moderate" category. This shows that there exists moderate relationship between accessibility, reliability and variety toward the customers' satisfaction. The Durbin-Watson value is calculated to be $1.907,1.741$ and 1.804 respectively for accessibility, reliability and variety. The values are closer to 2 indicating that it is non-autocorrelation. The results of R-Square for convenience is $10.3 \%$ demonstrate the strength of correlation between convenience and satisfaction is weak. The Durbin-Watson test recorded at 2.032, which is closer to 2 indicates that there is a non-autocorrelation between convenience and satisfaction. In other words, there is a weak influence on satisfaction when it comes to convenience, and convenience as a variable might not justify the level of satisfaction.

Table 5. Model Summary Predictors on Satisfaction

\begin{tabular}{cccccc}
\hline Model (Predictors - Constant) & $\mathrm{R}$ & $\mathrm{R}$ Square & Adjusted R Square & Standard Error of the Estimate & Durbin-Watson \\
\hline Time efficiency & 0.914 & $83.5 \%$ & 0.834 & 0.24786 & 1.557 \\
Cost efficiency & 0.917 & $84.0 \%$ & 0.840 & 0.24372 & 1.454 \\
Accessibility & 0.587 & $34.4 \%$ & 0.342 & 0.49361 & 1.907 \\
Reliability & 0.829 & $68.7 \%$ & 0.686 & 0.34084 & 1.741 \\
Variety & 0.761 & $58.0 \%$ & 0.578 & 0.39520 & 1.804 \\
Convenience & 0.321 & $10.3 \%$ & 0.100 & 0.57736 & 2.032 \\
\hline
\end{tabular}

Table 6 shows the ANOVA test done between time efficiency, cost efficiency, accessibility, reliability and convenience on satisfaction. The result shows that the $\rho$ value for all predictors are 0.000 which are less than $1 \%$, indicating that the result is significant at $1 \%$. The results supports direct influence between all the predictors and satisfaction.

Table 6. ANOVA Test of Predictors on Satisfaction

\begin{tabular}{|c|c|c|c|c|c|c|c|c|c|c|c|c|c|c|c|c|c|c|}
\hline \multirow{2}{*}{ Predictors } & \multicolumn{3}{|c|}{ Time efficiency } & \multicolumn{3}{|c|}{ Cost efficiency } & \multicolumn{3}{|c|}{ Accessibility } & \multicolumn{3}{|c|}{ Reliability } & \multicolumn{3}{|c|}{ Variety } & \multicolumn{3}{|c|}{ Convenience } \\
\hline & RG & RS & $\mathrm{T}$ & RG & RS & $\mathrm{T}$ & $\mathrm{RG}$ & $\mathrm{RS}$ & $\mathrm{T}$ & RG & RS & $\mathrm{T}$ & RG & $\mathrm{RS}$ & $\mathrm{T}$ & RG & RS & $\mathrm{T}$ \\
\hline $\begin{array}{l}\text { Sum of } \\
\text { Squares }\end{array}$ & $\begin{array}{l}\infty \\
\infty \\
\alpha\end{array}$ & $\begin{array}{l}\stackrel{\infty}{\circ} \\
\infty\end{array}$ & $\begin{array}{l}\stackrel{N}{\infty} \\
\dot{\Xi} \\
\Xi\end{array}$ & 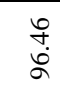 & 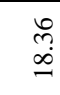 & $\begin{array}{l}\mathcal{I} \\
\stackrel{\infty}{ \pm} \\
=\end{array}$ & $\begin{array}{l}n \\
\ddot{n}\end{array}$ & શે & $\begin{array}{l}\tilde{N} \\
\dot{\Xi} \\
\Xi\end{array}$ & $\begin{array}{l}\infty \\
\infty \\
\infty\end{array}$ & $\ddot{m}$ & $\begin{array}{l}\stackrel{N}{\infty} \\
\dot{+} \\
=\end{array}$ & $\begin{array}{l}n \\
n \\
n \\
0 \\
0\end{array}$ & $\stackrel{m}{m} \underset{+}{\infty}$ & $\begin{array}{l}\mathcal{N} \\
\stackrel{\infty}{\Xi} \\
=\end{array}$ & $\stackrel{\infty}{=}$ & $\stackrel{\varrho}{\varrho}$ & 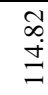 \\
\hline $\mathrm{df}$ & - & oे & $\stackrel{\circ}{m}$ & - & 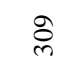 & $\stackrel{\circ}{m}$ & - & oे & $\stackrel{\circ}{m}$ & - & 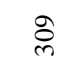 & $\stackrel{\circ}{m}$ & - & 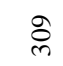 & $\stackrel{\circ}{m}$ & - & 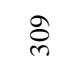 & $\stackrel{\circ}{m}$ \\
\hline $\begin{array}{l}\text { Mean } \\
\text { Square }\end{array}$ & $\begin{array}{l}\tilde{a} \\
\infty \\
2 \\
a\end{array}$ & ఫ̊ & & $\begin{array}{l}\text { +o } \\
\text { \&̊ }\end{array}$ & हे & & $\begin{array}{l}n \\
\tilde{m} \\
\tilde{m}\end{array}$ & 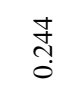 & & $\frac{\infty}{a}$ & $\begin{array}{l}0 \\
= \\
0\end{array}$ & & $\begin{array}{l}n \\
n \\
n \\
0\end{array}$ & $\stackrel{0}{\circ}$ & & $\stackrel{\infty}{=}$ & $\stackrel{m}{n}$ & \\
\hline $\mathrm{F}$ & 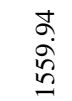 & & & $\begin{array}{l}\infty \\
\infty \\
\tilde{ర} \\
\underline{\sigma}\end{array}$ & & & $\begin{array}{l}\underset{i}{i} \\
\text { }\end{array}$ & & & ڤై & & & $\begin{array}{l}\stackrel{n}{0} \\
\stackrel{0}{\mathfrak{T}}\end{array}$ & & & $\begin{array}{l}\stackrel{m}{*} \\
\stackrel{m}{n}\end{array}$ & & \\
\hline Sig. & 0 & & & 0 & & $=\operatorname{Reg}$ & $\begin{array}{c}0 \\
\text { ressior }\end{array}$ & ; $\mathrm{RS}=$ & Resi & $\begin{array}{c}\circ \\
\text { lual; } \mathrm{T}\end{array}$ & $=$ Tot & & 0 & & & 0 & & \\
\hline
\end{tabular}

\section{CONCLUSION}

This paper has investigated the effect of implementing cloud based QMS on mobile users. The study is focused on the relationship of the independent variables, which are time efficiency, cost efficiency, accessibility, reliability, variety, and convenience towards the dependent variable, which is the customer satisfaction, has been concluded to have significant correlation, in a positive manner. Each of the independent variable, focuses on a different aspect of the system, which involves the use of mobile application, as well as, the implementation of cloud technologies. The recommendation for future study is implementing the same set of survey questions on samples that used the system, using a different dependent variable such as employee productivity, and investigating the effect of such system to an organization revenue. The results from the recommended study, will not only support the result for this study but will help organizations decide to implement or start using QMS integrated with cloud technologies and mobile application.

\section{ACKNOWLEDGEMENTS} J510050791.

The author gratefully acknowledged the funding of Universiti Tenaga Nasional YCU grant 


\section{REFERENCES}

[1] R. Ramli, et al., "Interaction testing for an ad-hoc system (queue management system)," ARPN Journal of Engineering and Applied Sciences, vol. 10, pp. 1161-1168, 2015.

[2] Y. K. C. Kim and H. Jung, "IoT task management system using control board," Indonesian Journal of Electrical Engineering and Computer Science (IJEECS), vol. 13, pp. 25, 2019.

[3] R. F. C. A. H. Ali and M. J. Mnati, "A smart monitoring and controlling for agricultural pumps using LoRa IOT technology," Indonesian Journal of Electrical Engineering and Computer Science (IJEECS), vol. 13, pp. $25,2019$.

[4] A. Stone, "Why Waiting Is Torture," in Sunday Review, ed. The New York Times, Aug 2012.

[5] S. Reporter, "Wait in line: Nearly a year of our life is spent in QUEUES," in SWNS News, Sep 2012.

[6] L. Maguire and S. Geiger, "Emotional timescapes: the temporal perspective and consumption emotions in services," Journal of Services Marketing, vol. 29, pp. 211-223, 2015.

[7] M. G. Farnworth, "A game theoretic model of the relationship between prices and waiting times," Journal of Health Economics, vol. 22, pp. 47-60, 2003.

[8] J. G. Cullis, et al., "Waiting lists and medical treatment: analysis and policies," Handbook of health economics, vol. 1, pp. 1201-1249, 2000.

[9] P. A. Simons, et al., "Cost-Effectiveness of Reduced Waiting Time for Head and Neck Cancer Patients due to a Lean Process Redesign," Value in Health, vol. 18, pp. 587-596, 2015.

[10] A. Wolfe, "Institute of Medicine Report: crossing the quality chasm: a new health care system for the 21st century," Policy, Politics, \& Nursing Practice, vol. 2, pp. 233-235, 2001.

[11] V. Europe. "Retailers risk losing loyalty as Brits spend 18 hours a year queuing," 2018. Available: https://www.visaeurope.com/newsroom/news/retailers-risk-losing-loyalty-as-brits-spend-18-hours-a-year-queuing

[12] M. S. Olusola, et al., "Queue management systems for congestion control: Case study of first bank, Nigeria," International Journal of Advanced Studies in Computers, Science and Engineering, vol. 2, pp. 54, 2013.

[13] R. Arun and P. Priyesh, "Smart queue management system using gsm technology," Advanced in Electronic and Electric Engineering, vol. 3, pp. 941-950, 2013.

[14] M. H. A. Wahab, et al., "Gsm based electrical control system for smart home application," Journal of Convergence Information Technology, vol. 5, pp. 33-39, 2010.

[15] K. S. Hasan, et al., "Cost effective GPS-GPRS based object tracking system," in Proceedings of the international multiconference of engineers and computer scientists, pp. 18-20, 2009.

[16] R. V. Krejcie and D. W. Morgan, "Determining sample size for research activities," Educational and psychological measurement, vol. 30, pp. 607-610, 1970.

[17] A. S. M. M. Hoque and Z. Awang, "Exploratory Factor Analysis of Entrepreneurial Marketing: Scale Development and Validation in the SME context of Bangladesh," in And Tourism Research Conference 20-22 April 2016, pp. 22, 2016.

[18] L. M. Connelly, "Pilot studies," Medsurg Nurs, vol. 17, pp. 411-2, Dec 2008.

[19] S. McCormack, et al., "Pre-exposure prophylaxis to prevent the acquisition of HIV-1 infection (PROUD): effectiveness results from the pilot phase of a pragmatic open-label randomised trial," The Lancet, vol. 387, pp. 53-60, 2016.

[20] J. T. Roscoe, "Fundamental research statistics for the behavioral sciences," Holt, Rinehart and Winston, vol. 2, 1975.

[21] S. D. Anastasiadou, "Reliability and validity testing of a new scale for measuring attitudes toward learning statistics with technology," Acta Didactica Napocensia, vol. 4, pp. 1-10, 2011.

[22] M. Tavakol, et al., "Assessing the skills of surgical residents using simulation," Journal of surgical education, vol. 65, pp. 77-83, 2008.

[23] P. Christine and R. John, "Statistics without maths for psychology -using SPSS for windows," Harlow, UK: Pearson Prentice Hall, 2004.

[24] V. Chang, et al., "Organisational sustainability modelling-An emerging service and analytics model for evaluating Cloud Computing adoption with two case studies," International Journal of Information Management, vol. 36, pp. 167-179, 2016.

[25] J. Akter, "Bootstrapped Durbin-Watson test of autocorrelation for small samples," ABC Journal of Advanced Research, vol. 3, pp. 68-72, 2014.

\section{BIOGRAPHIES OF AUTHORS}

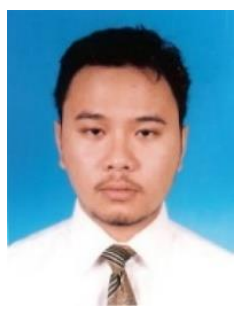

Aimran Hakim Mohd Saleh received his MEM from Universiti Tenaga Nasional in the year 2018 and BEEE (Hons.) from Pennsylvania State University in the year 2006. He is currently working as a Software Development Manager in Appspace (M) Sdn. Bhd. His research interests include, Software Defect Management as well as Software Architectural Designs. He has been working in the IT Industries for more than 10 years doing Software Development. 


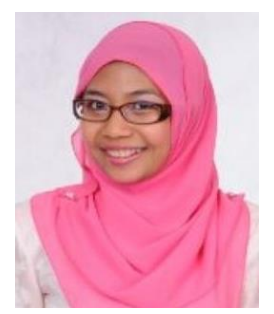

Nurul Asyikin Mohd. Radzi received her PhD. in Engineering, MEE and BEEE (Hons.) from Universiti Tenaga Nasional in the year 2013, 2010 and 2008, respectively. She is currently working as a senior lecturer in Department of Electronics and Communication Engineering, Universiti Tenaga Nasional. Her research interests include, optical communication and quality of service. She has contributed 50 technical papers in various journals and conferences. She is a senior member of IEEE Photonics Society and Chartered Engineer for IET.

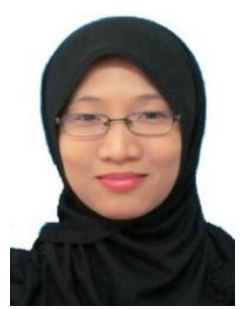

Wan Siti Halimatul Munirah Wan Ahmad received all her three degrees (the B.Eng. degree in Electronic Engineering majoring in Multimedia, M.Eng.Sc. and Ph.D.) from Multimedia University (MMU), Malaysia. She is currently a postdoctoral researcher at Universiti Tenaga Nasional (UNITEN), under UNITEN R\&D Sdn Bhd (URND), in modelling an algorithm for traffic scheduling project. Her main research interests are in the area of medical image analysis, content-based image retrieval, segmentation, feature extraction and data mining.

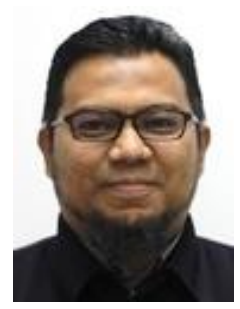

Mohd Rashidi Che Beson received his Bachelor of Engineering (Hons), MSc. and PhD in Communication Engineering from Universiti Malaysia Perlis (UniMAP) in 2007, 2009 and 2014 respectively. Currently, he is serving UniMAP as a senior lecturer and a principle investigator at Advanced Communication Engineering, Centre of Excellence - School of Computer and Communication Engineering, since 2014. His research interests lie in the strength of Optical CDMA technology, Radio over Fiber (RoF), Visible Light Communication, Horticulture and Fiber sensor technology. He has contributed 91 technical papers in various journals and conferences. He received his professional engineer qualification (Ir.) from Board of Engineer Malaysia (BEM) in March 2018 and professional technologist (Ts.) from Malaysia Board of Technologist (MBOT) in July 2018. He is an IEEE, IET members and was a committee of IEEE Photonics Society Malaysia Chapter for 2015-2016. 